issn: $1808-799 \mathrm{X}$

ano 5 - número 5 - 2007

artigo

\title{
Trabalho coletivo no MST: entre a utopia e a revolução
}

Sergio Miguel Turcatto*

\section{Introdução}

O objetivo central de uma pedagogia revolucionária, pedagogia esta que se realiza essencialmente através do princípio da associação entre trabalho e educação num processo singular e integrado, isto é, de uma pedagogia do trabalho, oposta à pedagogia do capital, era o de contribuir para a efetiva substituição de um sistema baseado na valorização do capital e da propriedade privada por outro baseado na valorização do trabalho e do trabalhador.

(ROSSI, 1981, v. 1, p.120).

No atual contexto mundial em que o capital se globaliza, aprofunda e amplia sua ação sobre os trabalhadores e trabalhadoras, pensar a questão do trabalho no campo, implica verificar suas contradições, tanto pela precarização das relações sociais, como pela tirania do livre comércio, seja na compra e venda da mão-de-obra, da produção e consumo de bens socialmente produzidos. Marx aponta que "a expropriação da grande massa da população, despojada de suas terras, de seus meios de subsistência e de seus instrumentos de trabalho, essa terrível e difícil expropriação constitui a pré-história do 
capital" (Marx, O Capital, 2002, p. 875).

Se por um lado a propriedade privada é a antítese da propriedade coletiva e social, por outro lado, a organização coletiva de trabalhadores, por superarem a concepção de trabalho manual/intelectual, sinaliza uma possível organização que vá para além do capital. Uma diminuta parcela dos excluídos do processo produtivo no campo, organizados politicamente, buscaram assegurar sua sobrevivência a partir da organização coletiva, com o intento de superar a pesudoconcreticidade do fenômeno na relação trabalho-capital. Entretanto, é possível que o trabalhador (a) do campo encontre na sua atividade laboral a dimensão formativa do trabalho, devido à precarização das relações sociais? Os trabalhadores organizados, como é o caso do Movimento Sem Terra, em que medida supera a visão economicista dentro do processo educativo do movimento? Há revolução no interior dessas relações de trabalho ou apenas é visto como algo utópico?

O trabalho não pode ser encarado como sinônimo de atividade em geral, mas como atividade produtiva especificamente, tornado-se o trabalho produtivo a mediação e instrumento pedagógico. A dimensão pedagógica e organizativa do trabalho possibilitou que trabalhadores e trabalhadoras encontrassem a maior expressão da sua coletividade. A dialética entre organização e liberdade constitui um desafio permanente às famílias envolvidas nesse processo de superação do trabalho alienado.

Com base nesse plano de análise que acabamos de destacar, pretendemos desenvolver os seguintes aspectos: o trabalho coletivo; as contradições contidas no trabalho coletivo ou no capital? e, para além das crises: possíveis revoluções ou apenas utopias.

Se hoje, por um lado o capital tenta de todas as formas e maneiras garantir o imperativo exacerbado do padrão de acumulação flexível, por outro lado, os trabalhadores (as) organizados criam alternativas que produzam o recuo do capital em determinados nichos? O MST se materializou ao longo de quase três décadas de história, como referência nacional e internacional de luta dos trabalhadores e trabalhadoras expropriados da sua força de trabalho e dos seus meios de produção da própria existência. $O$ pensamento único busca negar as tensões entre capital e trabalho, naturalizar as relações em todos os espaços em que imperam a exploração do homem pelo homem. Podemos indicar que a mudança está nas próprias tensões geradas no interior do próprio capital, e para superá-lo o possível caminho será através da mobilização/educação e organização da massa trabalhadora para a luta.

\section{O trabalho coletivo}

Para compreendermos a organização do trabalho coletivo dentro do MST é mister 
historicizar a formação e sua especificidade na região sul do Brasil, como também seu processo de materialização em todo o território nacional.

No histórico do sul do país, destacaremos três momentos importantes de tencionamento:
a) A constituição do MST se configura com o destino de imigrantes que é engendrado no processo de emprego e desemprego europeu. Com a mudança das pessoas, desloca-se também o eixo de uma grave crise que atravessa muitos países europeus. Em decorrência da imigração, cria-se uma poderosa sobrevida à acumulação capitalista no século XIX;
b) Apesar da especificidade, o MST não deixa de refletir a generalidade dos confrontos históricos e os problemas que desafiam a criatividade humana há um certo tempo;
c) O MST configura a luta entre o velho e o novo, entre uma sociedade que "verte água" e uma outra que pode ser vislumbrada nas franjas dessas relações sociais, cujo esgarçamento histórico vem se tornando irreversível na forma de nômades que vagueiam pelo mundo em busca de trabalho (AUED e FIOD, 2002, p.21)

A materialidade do Movimento Sem Terra no Oeste Catarinense ocorreu com a ocupação da Fazenda Burro Branco, no município de Campo Erê em maio de 1980, portanto, anterior à formação do acampamento da Encruzilhada Natalino, o qual foi estruturado a partir de dezembro de 1980.

A organização do MST naquela região é perpassada por três momentos específicos: a ocupação da Fazenda Burro Branco; o trabalho realizado pela Comissão Pastoral da Terra (CPT) e por alguns sindicatos dos trabalhadores rurais da região, através do levantamento, identificação e organização de famílias sem terra, com pouca terra ou com um número de filhos em que a propriedade não comportava a mão-de-obra; e pela ação políticoorganizativa dos Trabalhadores Rurais Sem Terra de forma autônoma no extremo-oeste catarinense.

A nível nacional, a luta pela ocupação de terras improdutivas ganha força a partir do Congresso da Comissão Pastoral da Terra (CPT) realizado em Goiânia, no ano de 1982. Em dezembro de 1984 foi realizado o I Congresso Estadual do MST, em preparação do I Congresso Nacional dos Trabalhadores Sem Terra, ocorrido no ano seguinte, em Curitiba.

Todos esses fatos materializaram o processo de preparação para as ocupações que ocorreu ao longo de dois anos no extremo-oeste catarinense. Em maio de 1985, mais de duas mil famílias sem terras ocuparam simultâneas áreas improdutivas em sete municípios daquela região. Até o final de 1986, o MST conseguiu desapropriar 22 imóveis 
em onze municípios, assentando 1200 famílias. Visto que o número de famílias acampadas era superior à quantidade de terra desapropriada, o movimento passa a verificar áreas de terra hipotecadas junto a bancos e órgãos públicos para proceder possíveis assentamentos.

Dentro desse contexto nasceu o Assentamento Conquista na Fronteira, através da compra de uma área de terra pelo Instituto Nacional de Colonização e Reforma Agrária (INCRA) na zona rural do município de Dionísio Cerqueira, Estado de Santa Catarina, a qual estava hipotecada junto ao Banco do Estado do Rio de Janeiro (BANERJ). A transação comercial entre o Banco e o INCRA, transcorreu sob o contrato de compra e venda, portaria no 215 de 04.03.1988. Em 24 de junho de 1988, 60 famílias tomaram posse de 1.198,24 ha de terra com o intento de trabalhar a terra e se organizar de forma coletiva.

O processo de formação do projeto foi conflituoso, pois lideranças políticas daquele município, contrárias ao Movimento Sem Terras, se empenharam em conturbar o processo de ocupação, reclamando a área para as famílias sem terra munícipes. O impasse foi superado junto ao INCRA, o qual estabeleceu que 35 famílias seriam do MST e 25 famílias daquele município. Os dois grupos trabalharam separados durante quatro anos. $A$ fundação da Cooperativa de Produção Agropecuária União Oeste Ltda (COOPERUNIÃO) em $1^{\circ}$ de outubro de 1990, materializou o sonho do trabalho coletivo dentro do assentamento e o fim da divisão interna do assentamento.

Em que medida o trabalho realizado de forma coletiva por aqueles trabalhadoras pode ser pedagógico? A alienação do trabalhador e da trabalhadora é superada?

Ao aprofundar a dimensão coletiva e pedagógica do trabalho, nos apoiaremos em dois pensadores: Lênin e Pistrak.

Lênin defendeu o princípio do engajamento revolucionário, com base na pedagogia do trabalho, postulando um caráter democrático e participativo, com base na autogestão coletiva. Destacou a importância dos intelectuais e a tarefa de conscientizar os trabalhadores, mediação necessária para transpor as contradições do capital. Para ele, a classe trabalhadora necessitava superar três grandes barreiras: da exploração, da ignorância e da pobreza , visto que a maioria dos trabalhadores estavam imersos em seus interesses imediatos. Assim, a educação é a mediação necessária para o processo de politização.

Já para Pistrak, o ponto de partida da questão do trabalho coletivo, aponta "todo homem é mais ou menos um criador, e é correto que, como coletividade, somos todos criadores" (PISTRAK, 2001, p. 25).

O trabalho é uma base excelente de educação, permitindo resolver os 
problemas de pura educação, mas não os problemas de ensino. Graças ao trabalho o homem se torna disciplinado e organizado: é preciso ensinar o amor e a estima pelo trabalho em geral. $O$ trabalho eleva o homem e lhe traz alegria; educa o sentimento coletivista, enobrece o homem e é por isso que o trabalho, e particularmente o trabalho manual de qualquer tipo, é precioso como meio de educação (PISTRAK, 2002, p. 48).

Desta forma, coletividade não apenas como justaposição de indivíduos, ou grupo de indivíduos, ou mesmo a junção das diferentes partes que constitui a totalidade. Numa determinada coletividade, a quantidade se torna qualidade, expressão real e completa do projeto social do sujeito. Concentra a riqueza de suas individualidades de cada ser humano, enquanto companheiros e iguais, condutores e produtores do próprio processo de crescimento.

O trabalho coletivo se fundamenta, segundo Pistrak (2002), em três aspectos importantes: o lador coletivo; a unificação do trabalho construído pelos subgrupos mediante a revisão comum; e a responsabilidade coletiva pelo trabalho. Visto que o trabalho produtivo/improdutivo é basilar para a coletividade, sua pedagogia se torna revolucionária, na qual a base produtiva daquele contexto pode ser transformada, pela mediação do trabalho coletivo e entre seus membros.

Os trabalhadores e trabalhadores do Assentamento Conquista na Fronteira buscaram no trabalho a condição de ontocriativo e, a dimensão organizativa, como mediação necessária de sobrevivência frente ao capital.

Destacaremos a seguir alguns aspectos necessários que engendram o trabalho coletivo, nesta especificidade do MST. Destacaremos a questão histórica, que resgata a precariedade das instalações no início da formação do assentamento, dificuldade de sobrevivência, a pobreza do solo, entre outros entraves. Organizaram-se internamente, tendo como base a democracia participativa ascendente[1] e descendente. Ansolim relata que,

... segundo o Regimento Interno, os objetivos definiam como metas: vida digna e igualitária para todos e todas as pessoas assentadas e apontava para a transformação da sociedade. O processo organizativo estava alicerçado em três etapas de produção: para a subsistência, para o comércio e a industrialização. Assim, o processo de ocupação da terra exigiu a ocupação das novas relações sociais, visto que no nível individual foram demasiadas, entretanto a associação pela cooperação possibilitava superar entraves da subsistência humana, tais como: As famílias se abrigavam em galpões, barracos e abrigo dos animais. O solo era muito pobre, e no inicio só se tinha uma junta de boi que era de um dos assentados. O primeiro recurso vindo foi pago horas de trator para lavrar e gobiar as terras que eram cobertas 
de grama, após a realização da safra acabou-se comprando este mesmo trator, apesar das dificuldades a produção aos poucos foi se desenvolvendo principalmente para a subsistência das famílias (ANSOLIN, 2004, p. 6).

Um segundo aspecto importa é a estrutura orgânica da Cooperunião, fruto do tempo e da realidade objetiva, consolidou-se através da organização do processo produtivo e das relações sociais de produção dentro do assentamento e pelas instituições do mercado. Atualmente a Cooperativa de Produção Agrícola (CPA) é composta de 107 sócios, com 135 pessoas envolvidas no processo produtivo, subdivididos em 7 equipes de trabalho de 25 tipos de produtos, divididos em 23 setores de produção.

O terceiro aspecto trata da qualidade de vida, segundo o desenvolvimento das unidades de produção, pois o assentamento é relativamente jovem em relação a seus membros, ampliando o processo de desenvolvimento da CPA.

Segundo levantamento junto à CPA, atualmente há centro e dez (110) pessoas que são estudantes ou já concluíram seus cursos, os quais foram totalmente beneficiados pelos resultados obtidos via mediação do trabalho político-organizativo cooperado.

O quarto aspecto é relativo à questão da subsistência, pois sempre foi prioridade para os assentados desde o acampamento. O primeiro elemento motivador do processo produtivo foi garantir alimentação para todos os envolvidos nesse novo momento histórico de vida de todas as famílias. A equipe de subsistência está organizada de modo a produzir todos os alimentos que compõem o cardápio das famílias, tendo como meta para este ano agrícola, exceder a produção necessária, comercializando produtos nas feiraslivres dos municípios vizinhos de forma a suprir os custos da produção.

Dentro do assentamento, a produção é dividida segundo a porcentagem de recebimento e da necessidade da cada família. São produzidos em torno de vinte e cinco (25) tipos de alimentos. Segundo a realidade objetiva, é possível visualizar a organização do processo de produção da própria subsistência das famílias assentadas, afirmando que a carestia foi definitivamente suplantada pelo processo de cooperação. Entretanto, trabalho coletivo tornou-se uma forma superior de organização autogerida pelos próprios trabalhadores e trabalhadoras?

\section{As contradições contidas no trabalho coletivo ou no capital?}

O capital contribuiu para o avanço das forças produtivas, com o desenvolvimento tecnológico, entre outros aspectos positivos. Dialeticamente produziu a fragmentação do trabalho, causando enormes perdas para a classe trabalhadora, alienando o produtor de mercadorias. O homo faber não se percebe como produtor do referido bem de consumo ou 
de uso, ou seja, o objeto criado não mais reflete o sujeito, sua atividade, o processo de objetivação. Segundo Lukács (1981), é pela objetivação que o ser social muda a natureza e muda a forma como ele se vê, através do domínio e do exame das suas capacidades, desabrochando a produção da ciência.

No caso do Assentamento Conquista na Fronteira, o processo de produção está alicerçado segundo o princípio da cooperação, forma de trabalho em que os assentados trabalham juntos. Pelo seu regimento Interno, art. II, dos objetivos econômicos, alíneas "a" e "b" : "Trabalhar toda a terra pertencente à cooperativa de forma coletiva'[e] "explorar racionalmente as riquezas naturais existentes de forma coletiva bem como tudo o que produzimos" (COOPERUNIÃO, Regimento Interno, 2003, p. 3). Isso denota uma forma superior de cooperação, concebendo a objetivação/subjetivação do ser social na sua totalidade.

A cooperação dos trabalhadores e trabalhadoras no assentamento acontece no processo produtivo e no processo improdutivo. Para o capital, a "a cooperação só começa no processo de trabalho, mas, depois de entrar neste, deixam de pertencer a si mesmos" (MARX, 2003, p. 386), os trabalhadores constituem um organismo que trabalha de forma coletiva. No assentamento, a cooperação é gestada pela auto-organização dos trabalhadores, não sendo de forma impositiva, assim, "o trabalhador coletivo tem olhos e mãos em todas as direções e possui, dentro de certo limite, a dom da ubiqüidade. Concluise ao mesmo tempo diversas partes do produto que estão separadas no espaço" (MARX, 2003, p. 380). Na medida em que o capital ordena as forças produtivas, nada lhe custa 0 trabalho coletivo desenvolvido gradativamente pelos trabalhadores, por outro lado, parece que essa força é natural e imanente ao capital.

A cooperação simples é a forma predominante nos ramos de produção operada pelo capital em larga escala. Para o MST e os assentados da Conquista da Fronteira o trabalho coletivo, enquanto modelo de produção, é assimilado como forma superior de cooperação segundo a realidade objetiva. A produção coletiva pelo coletivo condensa tamanha importância, no qual ocorre a formação integral do assentado de forma dialética.

No assentamento, os trabalhadores cooperado construíram uma associação de sujeitos, sem fins lucrativos, de natureza civil, não sujeita à falência, constituindo uma pessoa jurídica, mediação necessária na relação com o capital. "A cooperativa de produção assume personalidade jurídica distinta da pessoa do sócio, que a partir de sua fundação passa a construir sua própria existência, pela participação e envolvimento direto de seus associados" (CONCRAB, Caderno de Cooperação Agrícola, 1994, p.6). Para tal intento, cada associado contribui com cotas-partes, cujo objetivo é de compor o capital social na formação do capital da cooperativa. O patrimônio líquido da CPA se constitui pelo capital social, reservas e sobras ou perdas. 
É mister destacar pontos nefrálgicos de todo esse processo, destacados por Fontana (1999), Santos (2000), Christoffoli (2000), Dalmagro (2002). No Assentamento Conquista da Fronteira a contradição se faz presente, pois ao organizarem a sua própria Cooperativa de Produção Agrícola (CPA), o coletivo gerou expectativas. Entretanto, após dez anos o saldo é positivo no aspecto da organização, mas segundo Pedro Ivan Christoffoli, há necessidade de superação do estágio atual em que as cooperativas não conseguem atingir equilíbrio entre geração e consumo de riqueza e/ou competitividade frente à concorrência capitalista e portanto estariam inviabilizadas desde uma perspectiva econômica (CHISTOFFOLI, 2000, p. 88). Se a cooperativa não consegue gerar valor excedente de capital, o subsídio[2] torna-se a forma mas adequada para manter o coletivo e tem como conseqüência, endividamento da CPA[3].

Outra questão relevante, salientado por Christoffoli, foi a baixa produtividade do trabalho, advindo do "corpo mole" que alguns trabalhadores do coletivo fazem ao realizarem suas tarefas. Uma das explicações é que alguns associados sentem-se trabalhando para a cooperativa, restabelecendo a visão de patrão e empregado. Christoffoli afirma que

O "corpo mole" tem efeito direto e indireto sobre a produtividade geral do trabalho no coletivo. Direto porque a pessoa que faz "corpo mole" produz menos e contribui para rebaixar a média produzida no conjunto dos associados. E indireto porque gera dois efeitos desestimulantes: 0 desestímulo a outros trabalhadores que reduzem seu ritmo para adequá-lo à média do grupo (o que leva a um auto-reforço negativo) e pelo fato de gerar atritos entre as pessoas que criticam a atitude do "corpo mole", gerando desconfiança mútua e inimizades, etc. (CHRISTOFFOLI, 2000, p. 168).

Numa sociedade em a categoria de trabalho tem sua centralidade no valor, cujo elemento basilar é o lucro, o assentamento supera e é superado pela hegemonia do capital, produzindo crises dentro do próprio coletivo. Entretanto, é preciso historicizar, retomar à construção histórica da classe trabalhadora, a exemplo de Gramsci, que em seu tom construtor, quando os operários italianos não agüentaram a greve geral de 1922, ele alerta os líderes sindicais afirmando: "menos barulho e mãos à obra; é preciso recomeçar tudo de novo. $O$ operário que voltou a trabalhar porque não agüentou a fome, não deixou de ser revolucionário" (NOSELLA[4], 1992 apud GRAMSCI, 1966).

Segundo Dalmagro, o assentamento Conquista da Fronteira, além dos avanços na sua organização e da realização do trabalho de forma coletiva, elementos superiores à 
condição da maioria dos campesinos que vivem de forma Isolada, não configurou uma ruptura com o sistema capitalista de produção. A autora aponta:

O embate entre essas formas opostas é vivo, é palpitante, é motor do assentamento, é fonte de educação das pessoas. $O$ trabalho situa-se no entremeio dessa disputa: ao mesmo tempo que busca livrar-se da exploração e alienação, ainda não consegue ser totalmente criativo, autogestionado e emancipador. $O$ que de novo podemos observar no assentamento não reside no trabalho, mas na organização coletiva, que é a expressão do Movimento Sem Terra (DALMAGRO in VENDRAMINI, 2002, p. 146).

A organização do coletivo, tanto pelo MST como pelas famílias assentadas, tem elementos que estão na gênese de todo o processo, isto é, na centralidade do trabalho político-organizativo que se materializa através da prática dos princípios de uma organicidade, dando direção política a todas as frentes do Movimento: produção, educação, formação, saúde, tecnologia, etc, enquanto mediação e produção da existência humana. Será que esses indicadores não apontam para a formação do "novo trabalhador coletivo"?

\section{Para além da crise: possíveis revoluções ou utopias}

$\mathrm{Na}$ tentativa de controlar o poder reacionário do capital, os trabalhadores associados acentuam a importância da cooperação como elemento educativo e da superação de conflitos. Entretanto, uma das contradições enfrentadas pelos assentados e assentadas foi a ênfase à CPA, decorrente do imediatismo econômico e da necessidade de sobrevivência, causando um deslocamento da centralidade do trabalho coletivo pelo processo de cooperação das forças produtivas, adquirindo um viés economicista. Isso gerou um grau de insatisfação e resistência por parte de algumas famílias assentadas, seja pela baixa produtividade do trabalho/hora, seja pelas dívidas adquiridas pela cooperativa ou pelo baixo acúmulo de capital individual entre outros aspectos.

Para equacionar essa contradição, o MST propõe estrategicamente combinar a ação econômica com a ação política,

(...) mesmo que de forma insuficiente, pelas seguintes formulações: os assentamentos devem ser vistos de forma estratégica na organização e mobilização de massa e menos pela estruturação e competição econômica; estabelecer um relacionamento de cooperação entre todos sem desvincular a economia da política e da administração (CONCRAB, 1999, p. 14).

A forma de organizar o trabalho no assentamento denota um projeto pedagógico explícito para a grande maioria dos envolvidos. Tem por objetivo a construção de um certo tipo de trabalhador da agroindústria, que gera riqueza e também sobretrabalho para o 
capital, como para além dessa realidade. A forma de organizar as relações sociais de produção difere da tirania do sistema. O projeto educativo gestado pelos associados da Cooperunião, encontra resistência no conjunto das relações sociais, isto é, do processo educativo determinado pelo sistema capitalista.

Ao observar o caráter educativo do Assentamento Conquista na Fronteira é necessário verificar as diversas etapas de trabalho dentro da CPA, desde o planejamento até a execução.

O planejamento e a organização dos trabalhos na Cooperunião são de responsabilidade de todos os trabalhadores envolvidos. Ao final do ano agrícola, acontece o processo de avaliação da produção, como também a metodologia utilizada para a implementação do planejamento. Em seguida é formada uma comissão composta pelos membros do Conselho Diretor e do Conselho Social e Político para elaborar o anti-projeto para o ano agrícola seguinte, sendo que cada equipe de trabalho desenvolve o seu projeto de planejamento. A direção coletiva junta todos os projetos das equipes de trabalho, dá seu parecer, enviando uma cópia do projeto para cada núcleo de base, respeitando o método democrático ascendente. O planejamento passa por três instâncias de poder até chegar à assembléia: equipes de trabalho; direção coletiva; os núcleos de base do assentamento e por fim, a aprovação da assembléia. Assim, o planejamento contém um cunho de organicidade e estruturação do processo de trabalho coletivo. A aprovação acontece através do voto direto e por aclamação, com $50 \%$ mais um voto. Segundo o censo democrático, as propostas importantes são aceitas e aprovadas com 0 consentimento da grande maioria, evitando possíveis dissabores entre os associados no momento da execução das tarefas.

Após a aprovação, os coordenadores com suas equipes passam a executar os passos do planejamento com vista a atingir as metas propostas.

O processo de organização da produção é dinâmico, sendo ampliado e aprofundado segundo a experiência construída ao longo das atividades. A organicidade do assentamento está profundamente vinculada à estrutura orgânica da CPA.

Perante as múltiplas determinações das relações sociais na qual o poder do capital tem sua hegemonia, desafia cada trabalhador (a) a ser um intelectual orgânico, por um lado, é desfiado ir o além dos horizontes ideológicos do homem alienado ao capital, por outro, necessita encarar a sua verdadeira condição, segundo o contexto em que está inserido, para alcançar o objetivo desejado. Desta forma todo o processo histórico pressupõe mudança e permanência, ruptura ou continuidade com processo autoeducativo.

\section{Considerações finais}


No Assentamento Conquista na Fronteira as sessenta (60) famílias têm a possibilidade de experienciar uma forma de produção e de reprodução da vida, onde o movimento de negação e de afirmação dos trabalhadores (as), no movimento constante do processo de geração de individualidades históricas, engendraram a vida, a qual está perpassada pela totalidade da práxis social. O trabalho, o coletivo, a educação, a política, a autogestão são mediações fundamentais que produzem uma marca histórica na vida dos assentados como também a interelação entre gênero humano e indivíduo.

O Assentamento Conquista na Fronteira é fruto das contradições do capital e da organização do MST, pois materializou uma proposta alternativa de produção da própria existência humana. Na medida em que as famílias assumem um projeto de produção coletiva, criam instâncias de organização e poder, cuja democracia ascendente e descente indica a todos os envolvidos a necessidade de interagir no processo de construção do coletivo. Se, num primeiro momento, o econômico determinou a exclusão do sistema de produção e da existência humana, num segundo momento, o político afirma a necessidade de autogestão dos próprios trabalhadores (as). O trabalho torna-se o modelo da práxis social, na qual os indivíduos se constituem sujeitos do processo, tanto do valor de troca, como do valor de consumo. É nesse movimento que acontece a formação do sujeito, cuja realidade é permeada de contradições, de limites a serem superados individualmente e coletivamente. O assentamento é perpassado pelas relações capitalistas de produção, entretanto os sujeitos possuem consciência desse processo em determinados momentos, outros não, pois estão em perfeita sintonia com o poder hegemônico.

Muitas questões permanecem em aberto, condição do próprio movimento produzido pela realidade objetiva em que se encontram os sujeitos envolvidos, mas que são relevantes para avançarem na reflexão.

A primeira questão diz respeito ao modo como a pedagogia do trabalho produtivo/improdutivo poderá engendrar uma nova concretude do trabalho? Que instrumentos a dimensão educativa do MST poderá lançar mãos para auxiliar o (a) trabalhador (a) a superar o grau de alienação contida nas relações sociais de produção dentro do próprio assentamento?

A segunda questão versa sobre o nó entre as relações capitalistas de produção tanto fora, como dentro do assentamento, e o possível recuo das barreiras do capital dentro do projeto. Será que a organização da classe enfraqueceu seu caráter combativo frente ao processo de cooptação do capital, pois ao fazer concessões à forma de produzir a existência e aquisição de bens, não terão mutilado o projeto de objetivação socialista?

Por ser o capital um sistema social profundamente contraditório, é mister analisar a realidade com elementos norteadores capazes de apontar sendas, as quais contenham 
relações de cuidado com o ser humano, favorecendo a sua formação integral. Os assentados do Conquista na Fronteira possuem desafios até maiores do que a maioria da sociedade. Pois além de sobreviver no sistema de capital, ainda buscam desvelar elementos que materializem uma possível sociedade socialista, na qual o ser humano desenvolva plenamente suas potencialidades, sendo produto e produtor da própria história.

Assim, o mérito que o MST possui é ser um movimento de vanguarda da luta pela terra democratizada, e no seu $5^{\circ}$ Congresso pela Reforma Agrária, propõe justiça social e soberania popular.

\section{Bibliografia}

ANSOLIN, Tatiane A. Eficiência econômica dos principais produtos da Cooperativa

De Produção de Produção Agropecuária União do Oeste Ltda - COOPERUNIÃO Santa Catarina. Monografia. Veranópólis: TAC, 2004.

CONCRAB. A evolução da concepção de Cooperação Agrícola do MST (1989 a 1999).

SP: CONCRAB, 1999.

O cooperativismo no pensamento marxista. Caderno das experiências históricas da cooperação. № 2. SP: CONCRAB, 2000.

. Experiências clássicas da cooperação agrícola. Caderno das experiências

históricas da cooperação. № 3. SP: CONCRAB, 2001.

. Orientações jurídicas e contábeis sobre o funcionamento das CPAs: alguns

elementos.Cadernos de cooperação agrícola nำ2. SP: CONCRAB, 1994.

COOPERUNIÃO. Estatuto da Cooperativa de Produção Agropecuária “União do

Oeste" Itda. Dionísio Cerqueira: COOPERUNIÃO, 1990.

COOPERUNIÃO. Regimento Interno. Dionísio Cerqueira: COOPERUNIÃO, 2003.

COOPERUNIÃO. Projeto de produção de frango de corte. Dionísio Cerqueira:

COOPERUNIÃO, 2004.

DALMAGRO, Sandra Luciana. Trabalho, coletividade, conflitos e sonhos: a formação 
humana no Assentamento Conquista na Fronteira. Florianópolis:UFSC (Mestrado em educação), 2002.

FONTANA, Airton. Construindo o Caminho: uma educação orgânica - experiência do Assentamento Conquista na Fronteira. São Miguel do Oeste: UNOESC, 1999. FONTANA, Airton. (org.) Construindo a sustentabilidade: uma perspectiva para o desenvolvimento regional. São Miguel do Oeste: McLee, 2001.

FRANCO, Maria A. Ciavatta. O trabalho como princípio educativo: uma investigação Teórico-metodológica (1930-1960). (Tese de Educação) RJ: PUC, 1990. FRIGOTTO, Gaudêncio (org.). Educação e crise do trabalho: perspectivas do final século. Petrópolis, RJ: Vozes, 1998. A produtividade da escola improdutiva. (2 ${ }^{\mathrm{a}}$ ed.) SP: Ed. Cortez e Autores Associados, 1984.

FRIGOTTO, Gaudêncio e CIAVATTA, Maria. Teoria da Educação no labirinto do capital (2ª ed.) Petrópolis, RJ: Vozes, 2001.

GRAMSCI, Antonio. Concepção dialética da história. Rio de Janeiro: Editora Civilização Brasileira S.A., 1981. 4⿳亠丷a edição.

GRADE, Marlene. MST: Iuz e esperança de uma sociedade igualitária e socialista.

Florianópolis: UFSC (Mestrado em economia), 1999.

LÊNIN, Vladimir llitch. O desenvolvimento do Capitalismo na Rússia: O processo de formação do mercado interno para a grande indústria. $2^{\text {a }}$ ed., SP:Nova Cultural, 1985.

LISBOA, Teresa Kleba. A luta dos sem terra no Oeste Catarinense. Co-edição Movimento dos Trabalhadores Sem Terra. Florianópolis: Editora da UFSC, 1988. LUKÁCS, Georg. As bases Ontológicas do Pensamento e da Atividade do Homem. 
SP:Coleção Temas de Ciências Humanas, Editora Ciências Humanas, 1978. . Para uma Ontologia do Ser Social: O Trabalho. Tradução Prof. Ivo Tonet

(UFAL). A partir do texto // Lavoro, primeiro capítulo do segundo tomo de Per uma Ontologia dell'Essere Sociale. Roma: Editori Riunit, 1981 a. . História e Consciência de Classe: estudos sobre a dialética marxista. São

Paulo: Martins Fontes, 2003.

KONDER, Leandro. O futuro da filosofia da práxis: o pensamento de Marx no século XXI. RJ: Paz e Terra, 1992. A derrota da dialética. Recepção das idéias de Marx no Brasil até os anos

30. RJ: Campus, 1988.

KOSIK, Karel. Dialética do Concreto. (7ª ed.) Rio de Janeiro, Paz e Terra, 2002.

KUENZER, Acácia Z. Pedagogia da fábrica: as relações de produção e a educação

do Trabalhador._(6 ed.) SP: Cortez, 2002.

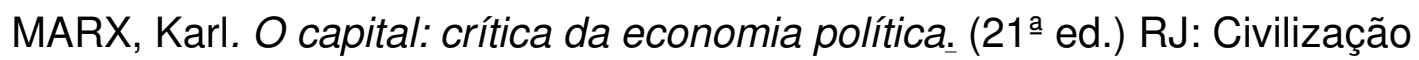

Brasileira, 2003. Livro I, v. 1,2.

. Capítulo inédito D’o Capital. Porto: Publicações escorpião, 1975.

. Manuscritos de 1844: economía política y filosofía. Buenos Aires: Ediciones

Estudió, 1972.

. E ENGELS,Friedrich. A ideologia Alemã. SP: Martins Fontes, 2002.

MÉSZÁROS, Isteván. O século XXI : socialismo ou barbárie?SP: Boitempo Editorial,

2003.

MST. Programa de Reforma Agrária. Caderno de Formação ํo 23. SP:3ํed., 1998. . Normas gerais do MST. SP: MST, 1989 
. Mística, uma necessidade no trabalho popular e organizativo. Caderno de

formação 27. SP: MST, 1998 a.

. Caderno de educação. № 9. SP:MST, 1999.

. Princípios da educação no MST. Caderno de educação no 8. SP: MST, 1999.

PISTRAK, M. Fundamentos da escola do trabalho. $2^{\text {a }}$ ed. SP: Editora Expressão

Popular Ltda, 2002.

NOSELLA, Paulo. A escola de Gramsci. Artes Médicas, Porto Alegre, 1992, p. 53.

POLI, Odilon. Movimentos sociais. Chapecó: Grifos, 1999.

ROSSI, Wagner Gonçalves. Pedagogia do trabalho: raízes da educação socialista. São

Paulo: Moraes, 1981, v.1., p.120).

SANTOS, Édina dos. Estudo organizacional e sócio-econômico do Assentamento

Conquista na Fronteira - Dionísio Cerqueira/SC. Monografia de bacharelado em Geografia da UNIOESTE: Francisco Beltrão/PR, 2000.

SILVA, Roberta Maria Lobo da. A dialética do Trabalho no MST: a construção da

Escola Nacional Florestan Fernandes Tese (Doutorado em Educação) - UFF: RJ, 2005.

TURCATTO, Sérgio Miguel. Elementos norteadores da ação pedagógica do MST no

Final da década de 90 no Assentamento Conquista na Fronteira. Niterói:UFF (Monografia), 2003.

VENDRAMINI, Célia Regina. Terra; trabalho e educação: experiências sócio

-educativas em assentamentos do MST. ljuí: Ed. Unijuí, 2000.

.(org.) Educação em movimento na luta pela terra. Florianopolis: NUP/CED,

2002.

file://C:LDocuments and Settings\Administrador|Meus documentoslMinhas WebslNED... 11/9/2008 
WOOD, Ellen Meiksins. A origem do capitalismo. Rio de Janeiro: Jorge Zahar

Editor,2001.

(*) O autor é mestre em Educação (UFF), professor de filosofia na Unilasalle e professor-substituto na Faculdade de Educação da UFF

[1] Democracia ascendente refere-se à primeira etapa das discussões, as quais são efetivadas nos núcleos de base, com o objetivo de esclarecer e aprofundar propostas e questões normativas entre os associados. A etapa seguinte será o encaminhamento às instâncias de coordenação, sendo definidas e remetidas ou não para a instância máxima, ou seja, a Assembléia. Após a aprovação, as resoluções entram na terceira etapa, ou seja, a democracia descendente, cujo objetivo é assegurar o eficiente cumprimento das decisões tomadas por todos os associados. Os espaços de discussão já estão superados, pois é a etapa da execução, onde a democracia participativa implica o cumprimento das decisões previamente tomadas nas instâncias coletivas.

[2] São linhas de crédito oferecido pelo Estado, via Banco do Brasil ou Caixa Econômica Federal como forma de auxiliar na produção de alimentos a baixo custo ou taxas de juros abaixo do mercado.

[3] Cooperativa de Produção Agropecuária: são unidades autogestionadas que reúnam a totalidade dos trabalhadores rurais, em condições de exercício de propriedade e posse coletivas sobre os meios de produção (executando-se a propriedade da terra em alguns casos), onde o trabalho dos associados é organizado mediante planejamento e normas coletivas autonomamente decididas e em que os resultados de produção são distribuídos com base na participação do trabalho de cada associado (CRHISTOFFOLI,2000:26).

[4] NOSELLA, Paulo. A escola de Gramsci. Artes Médicas, Porto Alegre, 1992, p. 53.

volta

file://C:LDocuments and Settings\Administrador\Meus documentos\Minhas Webs\NED... 11/9/2008 